\title{
A Quantitative Study of High Intake of Fruits and Vegetables and Prostate Cancer Risk in Men: A Meta-Analysis of Observational Studies
}

Elonye, Bede John ${ }^{1}$, Robinson, Ebbi Donald ${ }^{2 *}$, Agboje, Anthonio Azuka ${ }^{2}$, Omodu Ovunda Jack ${ }^{2}$

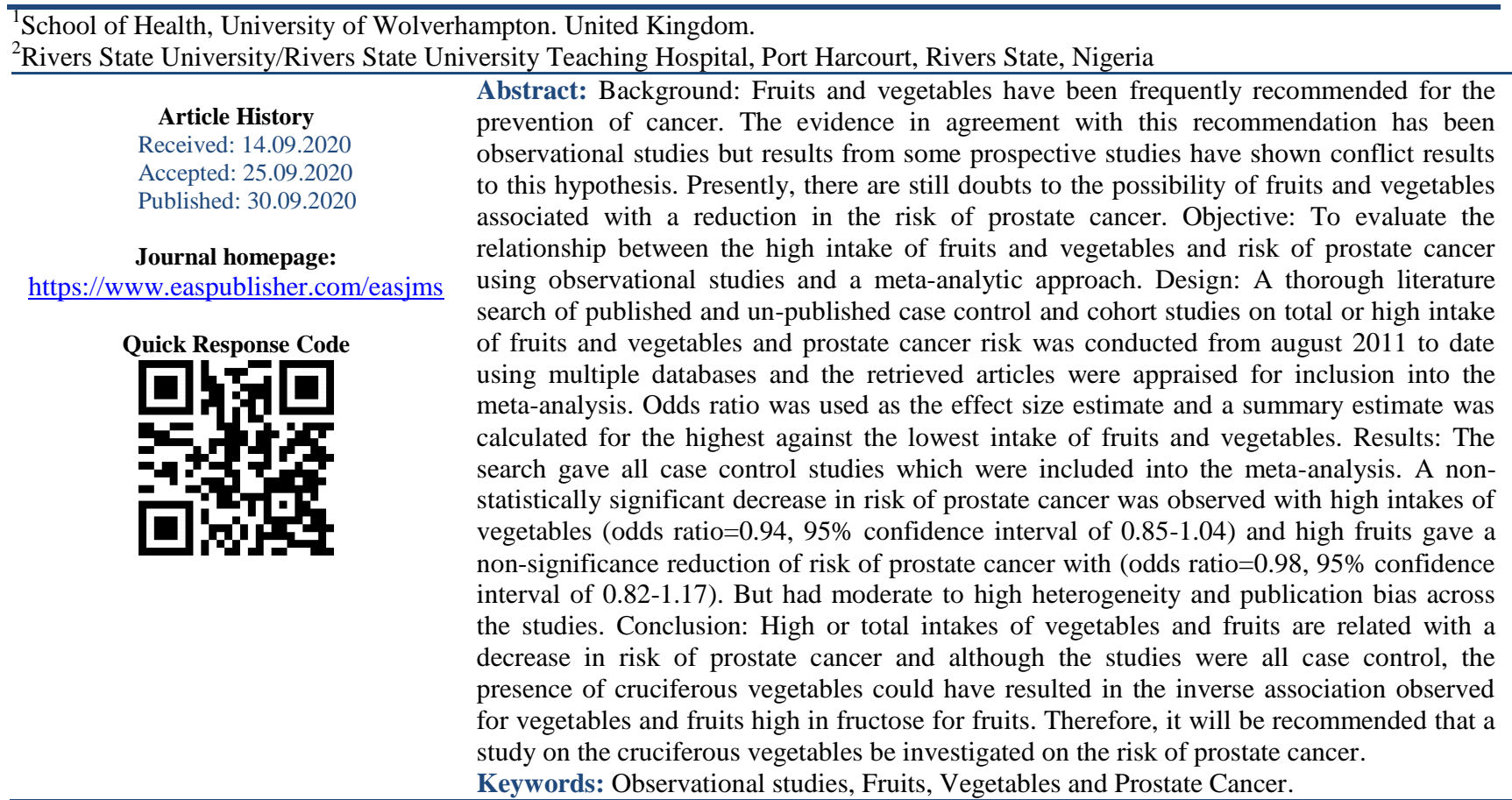

Copyright @ 2020: This is an open-access article distributed under the terms of the Creative Commons Attribution license which permits unrestricted use, distribution, and reproduction in any medium for non-commercial use (Noncommercial, or CC-BY-NC) provided the original author and source are credited.

\section{INTRODUCTION}

The prostate gland is an accessory sex gland of the male reproductive system with the physical appearance of a chestnut in shape and size 1. It is anatomical located at the base of the bladder and consisting of three lobes which are joined closely together [1]. The adult prostate gland is estimated to weigh about 50 grams with its size being influenced by the male hormone testosterone during puberty [2]. During puberty its growth is rapid before settling to a more gradual increase in size with advancing age which scientists have argued to be the changes in the level of testosterone with ageing [3]. Experimental research has shown that prostate cancer arises from a process termed carcinogenesis which involves cumulative changes in a cell's gene resulting in uncontrolled proliferation, differentiation and metastatic spread [1].
Prostate cancer is the most common non-skin solid tumour and considered as the third most commonly diagnosed cancer affecting men [4]. It is globally the fifth commonest cancer overall that affect the human race and the sixth leading cause of cancer death among men [4]. Over the years, there has been an accumulated impression among scientists and researchers that an environmental factor might play a major part as a risk factor for its cause or alternatively, be a measure for its prevention outside medical intervention [5]. Furthermore, numerous epidemiological studies conducted have revealed varying factors like ethnic background, age, genetic and particularly diet may influence the risk of developing prostate cancer [6]. Apparently, almost all of these studies have agreed to a regular diet containing fruits and vegetables as a modifiable risk factor which could reduce the risk of prostate cancer [7]. This view held by researchers that the frequent intake of plant food might slow down or prevent the appearance of cancer is linked 
to them containing anti-carcinogenic substances which inhibit the growth and proliferation of cancers [7].

Although, there are numerous studies which have supported the above hypothesis, but most of them have been insignificant [8]. Furthermore, reviews of some studies have highlighted that this association between prostate cancer and consumption of fruits and vegetables have been inconsistent [9]. On the hand, recent studies involving vegetables like cruciferous vegetables \{cabbages, broccoli, turnip, brussel-sprouts, cauliflower\} unlike fruits have been generating substantial evidence to support this hypothesis [10]. The report given by the American national cancer institute [11] that at autopsy, microscopic evidence of prostate cancer is found in majority if not all men and that there is a probability that 1 in every 6 men will be diagnosed with prostate cancer during his lifetime shows the imperial importance of this cancer. In addition, the gradual elimination of some other fatal diseases combined with a rising life expectancy means that the prevalent population will be the ageing population, where the burden of cancer is much more important than other diseases [23]. Prostate cancer being a cancer which is associated with advanced age has raised serious concerns among public health professionals in all sectors of health and, if diet does reduces the risk of developing prostate cancer later in life, a conclusive study would positively boost the health promotion and policy made by governmental and non-governmental institutions on nutrition/diet.

\section{Prostate Cancer and Fruits and Vegetables (Diet)}

Over three decades researchers have been interested in the possibility that fruits and vegetables consumption might contribute to the prevention or reduction of ailments ranging from minor headaches to chronic diseases like cancer of the prostate [12]. Following careful review of results from studies conducted on prostate cancer and diet, it was suggested that some dietary factors including plant foods could have significant protective effect on cancer risk [13]. Most research studies conducted since then have further added more emphasises to an association between prostate cancer and diet by demonstrated that persons with low fruits and vegetables consumption had a likelihood of experiencing twice the risk of developing prostate cancer compared to those with high intake [14].

Evidence from these studies led to the inauguration of the $5 \mathrm{~A}$ day for better health in the United States and a similar program in the Netherlands [15]. In view of the weight of this evidence from these conducted studies, the World Cancer Research Fund supported by the American Institute for Cancer Research 1997 concluded to the association between prostate cancer and fruits and vegetables through their report which they rescinded 10 years later. The association was questioned by larger prospective studies [16-18], which held views and findings of inconsistent for fruit but likely for vegetables in regards to reducing the risk of prostate cancer [19].

Despite the report of the panel, evidence supporting the consumption of fruits and vegetables especially cruciferous vegetables with reduced risk of prostate cancer continues to accumulate and experts attributed this growing epidemiological evidence to some specific fruits and vegetables that actually might exhibit potential benefit to cancer prevention [20]. Subsequently, extensive research has identified that fruits and vegetables, including cruciferous vegetables possess some specific constituents like micronutrients and phytochemicals which research has discovered to exert protective effect through generic as well as cancer specific mechanisms like antioxidant activity, induction of detoxification enzymes, stimulation of immune reaction, modulation of hormonal level, inhibit malignant transformation and modulating cell cycle [12].

Chemoprevention of prostate cancer is currently the trend of investigation among scientists. It has the potential of charting a new method to the treatment and management of prostate cancer in the $21^{\mathrm{st}}$ century [21]. Several nutrients have been identified to have inhibitory function towards formation of cancer cells and condition of hyper proliferation of cells [20]. These include constituents like phytoestrogens, isflavones, vitamins and micronutrients like selenium and others. Apart from these been suitable for pharmaceutical development, two agents have been identified to possess qualities that can be useful if clinical trials are perform on them;cox-2 and iGf-1 [22].

\section{Epidemiology of prostate cancer}

Prostate cancer is recognised as the sixth leading cause of cancer death globally but the leading cause of cancer death in African region and in the low and middle income countries of the region of the Americas [23]. It usually occurs in men above the age of 50 and rarely occurs below except as a result of genetic predisposition [24]. This makes it popularly known as a disease of elderly men where diagnosis is made between the ages of 60 to 90 years with a greater predilection for men from Africa or of African descent than the Caucasians or Asians [2]. According to Globocan [4], the number of newly diagnosed cases of prostate cancer was estimated at 899,000 with more than half of these diagnosis recorded from developed countries while it recorded 258,000 cases of deaths worldwide. Figures of 644,000 and 136,000 from the report were contributed by more developed regions for incidence and mortality rates respectively. While, 255,000 and 121,000 incidence and mortality rates from less developed regions [4].

\section{Diagnosis of prostate cancer}

It is rational that a cancer of this nature would benefit from early detection and treatment which 
improves the quality of life, as well as prevent deaths due to its metastatic spread [25]. Frequently, it is diagnosed by a combination of digital rectal examination, prostate specific antigen estimation and trans-rectal ultrasound or applying them separately. In addition, some facilities with up to date technology, would follow it with a biopsy to grade and determine the treatment modality for the cancer [26].

Currently, clinicians have agreed that the improved survival outcome achieved with the treatment of prostate cancer has been attributed to its early detection following the introduction of prostate specific antigen screening [26]. On the contrary, its uneven adoption in all regions of the world has been linked to the disparity in the incidence and mortality rates of prostate cancer [4]. Apart from prostate specific antigen, present research studies have revealed other advance techniques been put into practise in detecting and screening early, intermediate and advance cancers, such as human kallikrein,mass spectrometry, power Doppler imaging, lndium 111 prostascint and positron emission tomography which are meant to enhance the quality of life experienced by those inflicted [26].

\section{Treatment of prostate cancer}

Treatment of prostate cancer like any other cancer treatment has a specific treatment options which depends on whether the cancer was detected early or late based on patient's presentation to the examining clinician [27]. Subsequently, the best or most favourable treatment option is discussed with the patient prior to initiation of treatment. Essentially, if the prostate cancer is detected early and found to be localized within the prostate gland, a curative surgery called radical prostatectomy can be performed, that is surgical removal of the prostate gland and associated structures or radiotherapy is offered based on the patient's fitness to withstand the treatment and likely side-effects [28].

On the other hand, if the cancer is detected late and has advanced to affect other structures as previously mentioned above, the treatment modality is to give a hormonal therapy with the principal aim of relieving the symptoms than attempting a cure based on the poor prognosis of surgery at this late stage [29]. Furthermore, surgical removal of the testes is offered as a treatment for advanced cases but 99 percent of the time patients refuse from their understanding of its overwhelming side-effects [26].

\section{Constituents and Mechanism of action of fruits and vegetables}

The preventive or therapeutic effects of fruits and vegetables is by means to accidental discovery, rather even before the birth of Christ, plants have been utilizes in the treatment of cancers including prostate cancer [22]. However, this observation was not fully understood and had prompted several studies over the years to focus on the bioactive constituents of plants to understand the mechanism of their cancer preventive properties [7]. Some of these constituents are ubiquitous whereas others are specific to particular class of vegetables like the cruciferous vegetables [12].

A review study by Susan [30] concluded that over the years, all the constituents presently studied can be classed into phytochemicals, antioxidant substances and micronutrients. Vegetables and fruits are very rich sources in antioxidant substances and micronutrients, and Ames [31] suggested that deficiency in them gives arise to the association of low intake of fruits and vegetables and risk of developing prostate cancer. Antioxidants of importance are Vitamin A, C, E, B6 and Folic acid, where they all act by protecting the cell membrane, DNA and RNA from oxidative damage by the cancer cell [32]. Micronutrients present in fruits and vegetables which have shown epidemiological evidence to prostate cancer risk are selenium and magnesium, where they act by causing detoxification via redox reaction and peroxidation involving Adenosine triphosphate reactions [33]. Of the three constituents highlighted, most nutrition research studies according to Cooper et al. [34] Concentrated significantly on the phytochemicals which scientists have revealed to be numerous but few have been concluded to be relevant to prostate cancer prevention. These selected phytochemicals play very importance role in the anticarcinogenic properties associated with fruits and vegetables [12]. Thus, further discussion on them is essential. The organosulpur compounds are cruciferous vegetables like cabbages, broccoli, and cauliflower .etc. studies have observed them to be effective in cancer reduction because of their rich content of vitamins, minerals, low fat and high phytochemicals [32]. The vitamins present in cruciferous vegetables possess high antioxidant strength and it confers this vegetable with its anti-carcinogenic attributes [3]. The polyphenols are phenolic compounds and they are plants metabolites [31]. Fruits have more polyphenols than any other plants food and they comprise a major part of our diet intake [34]. Flavonoids and phenolic acid are the commonest of this phytochemicals in this group or class. They are also known to possess high antioxidant properties and have been linked to chemopreventive research studies [33].

Derivatives of phenolic acid are present in significant amounts in our daily diet, for example hydroxycinnamic acid, is such a derivate of phenolic acid and is present in many fruits like apple, grape and plum [31]. Flavonoids are also found in food items and they form a large proportion of phenolic compounds [12]. They are divided into 3 types and occur in red wine, chocolate and tea [32]. Studies have argued that this type of phytochemical can be useful in reducing the mortality of prostate cancer by drinking green tea [33]. Evidence supporting the studies mentioned above is those concerning the consumption of tea and the 
reduced risk of developing reproductive tract tumours [3]. The mechanism of action of the polyphenols involves suppressing the endothelial cells which the cancer of the prostate need for achieving uncontrolled growth and proliferation [12].

The next phytochemical of vital importance are the Carotenoids. They are common and found in almost all dark green, yellow, orange vegetables and red fruits and vegetables that are edible [7]. Presently, they are totally 60 in number and studies have documented that 40 are naturally occurring while 20 are existing in humans [34]. In humans, six are present in the highest concentration and they are also a good source of retinol in the body. Studies have argued that their low level in the blood has increase the development of epithelial cancers and likewise prostate cancers [32].The mechanism of action involves blocking the pathway of the tumour cells to oxygen by extinguishing the supply of peroxyl radicals. This function is commonly exhibited by one of the carotenoids, that are betacarotene [33].

The phytoestrogens is another phytochemical present in plants as estrogenic compounds. They exists in various forms and has their structures similar to the naturally occurring oestrogen hormone in the human body [35]. A popular plant food that contains this phytochemical is soybean. Soybean is commonly eaten in Asia \{i.e. Japan and China\} and studies have repeated concluded it to play a major role in the low risk of prostate cancer in this population [9, 24 and 36].

The mechanism of action of phytoestrogen is the inhibition of oxygen uptake by tumour cells, blocking an oestrogenic enzyme (oestrogenic synthetase) and mopping up of free radicals in the system [3]. The phytochemical, glucosinolate is made up of isothiocyanates and indoles which are the main constituents present in vegetables that are referred to as brassica [12]. The anti-carcinogenic mechanism varies from detoxification of carcinogen and foreign bodies to performing function of other phytochemicals that is blocking the estradiol hydroxylation channel and in turn inhibit estrogenic related tumours [37]. However, a study by Ames 1998 [31], indicated that anticarcinogenic constituents are not restricted to phytochemicals alone. He argues that micronutrients are equally important but less frequently researched by scientists due to their very small quantity.

According to Ames 1998 [31], these groups are currently estimated to be 40 in number and are well distributed in fruits and vegetables. Some experts have suggested that these micronutrients are implicated in prostate cancer and other cancers from their deficiency in low fruits and vegetables intake [9]. The important micronutrients are; vitamin A,C,E,B6 and Folic acid and the study done by Susan, [30] reported that these micronutrients perform almost the same anti- carcinogenic function of increasing the natural killing function of the body through their antioxidant properties. In summary, these constituents demonstrated their mechanism of action to be via prevention of formation of reactive oxygen and nitrogen species causing oxidative damage, increasing activity of enzymes involved in detoxification of carcinogens and preventing proliferation of endothelial cells [12]. However, studies reveal that there are still numerous constituents that are yet to be fully identified and according to Greenwald et al. [3], quantifying all the constituents present in whole food is a challenge which makes interpreting the association between them and prostate cancer inconclusive.

\section{Reasons for using Meta-analysis}

Over the years there has been a massive growth in the volume of research studies on intake of fruits and vegetables and the risk of prostate cancer where variety of methods with varying quality have produced contradictory findings [38]. Therefore, information from these studies has appeared to be inconclusive and difficult to make sense of its growing knowledge base by researchers, research funders and policy makers [39]. In accordance with evidence based medicine, this research will attempt to adopt the technology available to pull together all existing and available studies done on this topic to give a conclusive synthesis of the results of different studies using a metaanalysis [40].

This research considered to use a metaanalysis over other traditional reviews, to reduce the random error and increases precision [38]. It wills also being less influenced by the personal views of the researcher in producing an unbiased conclusion and, moreover creates an avenue for a reader to recalculate the data in comparison to the researcher conclusion [4].

Numerous epidemiological studies investigating the relationship between prostate cancer and intake of fruits and vegetables especially cruciferous vegetables has established that, while some demonstrated reduction in the risk of developing prostate cancer $[9,10,41,42,43]$ in those whose diet has moderate to high quantity of fruit and vegetables than non-takers. Others reveal no association between these variables $[16,44,45,46]$. Consequently, this study aims to conduct a meta-analysis which is stated as follows: Does consumption or intake of high vegetables and fruits reduce the risk of developing prostate cancer in men? The study will establish whether there is an association and equally evaluate the degree/strength of the association between high intake of vegetables especially cruciferous vegetables and fruits and risk of prostate cancer in studies conducted among adult men in different locations around the world to achieve a generalized result. It will also provide a quantitative evaluation in a standardized form permitting a numerical analysis across the studies that is estimates of 
odd ratio or relative risk and confidence interval from combination of multiple studies will be provided.

\section{Methodology}

A meta-analysis like any other research starts with a careful statement of a topic to be investigated or a well formulated question to be answered [47]. A thorough literature search of published and unpublished case control and cohort studies on total or high intake of fruits and vegetables and prostate cancer risk was conducted from august 2011 to date using multiple databases and the retrieved articles were appraised for inclusion into the meta-analysis. Odds ratio was used as the effect size estimate and a summary estimate was calculated for the highest against the lowest intake of fruits and vegetables.

\section{The literature search strategy}

The search was conducted to identify those studies which investigated the association and the strength of the association between intake of high fruits and vegetables and risk of prostate cancer. The extensive search done to retrieve all available studies which examined prostate cancer with intake of fruit and vegetables was carried out mainly using computerized indices and databases.

Relevant studies were obtained by carrying out a systematic and detailed search of the electronic database of the NHS core collection of databases. It is a set of eight different databases that can be searched via the dialog data star web platform and provided by the electronic resource of the learning centre of the University of Wolverhampton. It includes:

1. Allied and Complementary medicine -1995 to date (AMED).

2. CINAHL(R) - 1982 to date (NAHL).

3. British Nursing Index - 1994 to date (BNID).

4. DH-DATA - 1983 to date (DHSS).

5. EMBASE-1974todate(EMZZ)

6. King's Fund -1979 to date (KFND).

7. MEDLINE - 1996 to date (MEDL). and

8. Psycho Info - 1806 to date (PSYC).

The search was conducted between the period of August 2011 to January 2012 and no time range was given for the date of publication to allow an exhaustive identification of studies by the databases. In order to achieve a comprehensive search of the databases, other databases which were considered as relevant were accessed to identify and retrieve studies like Google scholar, Cochrane library and Science direct.

In carrying out an effective search, choosing the right set of keywords that correctly identify the topic is crucial [47]. This process involved retrieving published articles from all the databases, so as to attain a correct reference list. It begins by first deconstructing the topic into component concepts or subtopics.
Subsequently, as suggested by Glasziou et al [48], is followed by broadening the search criteria by finding alternative words that would reflect the association between the subtopic and lastly combining them with Boolean operators like (AND,OR, NOT) to give an exhaustive and precise search [39]. Thus, an initial restricted search with the keywords prostate cancer and fruits and vegetables was first attempted and later expanded by the following keywords:

\section{Prostate Cancer OR Prostate Carcinoma OR Prostate Neoplasms \\ Fruits OR Vegetables OR Diet \\ Fruits AND Vegetables OR Nutrition \\ Risk factor(s) AND Prostate Cancer \\ Cruciferous Vegetables OR brassica AND Prostate Cancer \\ Chronic Disease(s) AND Diet \\ Chronic Disease(s) AND Nutrition, Cancer(s) AND Nutrition}

The keywords search was adequately entered into the databases. The basic search modes of the databases of the NHS core collection are arranged as three search boxes. They allow key words to be entered individually and are connected by Boolean operators (AND, OR, NOT) that are freely chosen by the researchers.

Retrieving studies for a study needs to be comprehensively done and no matter how useful electronic databases are in achieving this purpose, there are few relevant papers that would be missed [39]. Other methods employed includes: snowballing, hand searching of journals, conference proceedings and writing to experts.

\section{Data Extraction}

The full text articles that were retrieved from the detailed appraisal of relevant articles, had each study carefully read and key information extracted. Some information extracted from the studies includes the author's name, the location in which the study was done, the year of publication, population size, number of cases with highest consumption of fruit and vegetable and number of cases diagnosed with prostate cancer. This meta-analysis used the odds ratio as a measure of the effect size statistics because it measures the probability of a particular event happening, which in this case is the risk of developing prostate cancer when exposed to fruits and vegetables. Although, considering the fact that odds ratio is more adapted to measuring of common than rare diseases or events which prostate cancer is, study outcomes measured in risk ratio would be approximated to be equivalent to odds ratio during the process of extraction of data from cohort studies. The extracted information is summarized in the following table. 1 to 4 below. 


\section{Data Summary and synthesis}

The vital information was extracting and inputted into RevMan software program for analysis. The results of individual studies which is the effect size estimate expressed as the odds ratio, was pooled together to provide a summary estimate. Heterogeneity within all the included 5 studies was assessed using the Cochran's Q test and I2 index or test [38]. Thus the P index has been proposed to quantify the degree of heterogeneity, while the Cochran's Q test tells the researchers of the presence or absence of heterogeneity but not its extent [39].

In this meta-analysis, the summary estimates of the 5 included studies were combined using the Mantel-Haenszel method based on the assumption Of the existence of a single true value that all included studies are estimating to measure in which the fixed effect model is founded on. In addition, results from this meta-analysis were graphical represented by forest plot.

\section{RESULT}

Figure 1, shows a comparison of high intake of vegetables and risk of prostate cancer in the 5 studies include in this meta-analysis with detailed information about the studies such as the author's name, year of publication, number of events/number of subjects included in the study. It also gives the odds ratio and confidence interval of each study and the pooled odds ratio. Thus it can be seen that a total of 6417 participants were involved in this particular analysis which comprised of 3183 cases/study group and 3234 control group. The number of participants who consumed vegetables was compared between case and control groups and the control had higher consumption of 1488 to 1411 of case. This can be attributed to some studies in which the control participants must have been more interested in health and more likely to have diets high in vegetables. The above result also indicated the Cochran's $\mathrm{Q}$ test which is the test for heterogeneity as represented by the Chi-square (4.20) and p-value (0.38) is not significant under the hypothesis of homogeneity (p>0.05) at 4 degree of freedom (df; number of studies 1) for OR (MH) which means that it is assumed that the studies taken as a group gives an estimate of the same outcome effect.

Thus, with no significant heterogeneity shown by all the studies, it fits well under the criteria of the fixed effect model which was used to combine their individual odds ratios using the Mantel- Haenszel method. This gave a pooled odds ratio of 0.94 at $95 \%$ confidence interval of $(0.85,1.04)$. Furthermore, the result also supported the test for heterogeneity by given the $\mathrm{I}^{2}$ index of $5 \%$ indicating no heterogeneity when compared to the criteria of $25 \%$ for mild heterogeneity, $50 \%$ for moderate heterogeneity and $75 \%$ for high heterogeneity. Looking closely at Figure 1, it reveals that of all the odds ratios for the individual studies, only one fell above 1.0 and a range of 0.64 to 1.03 . The implication is that there was only one study with a positive relationship, (i.e. high intake of vegetable increasing the risk of getting prostate cancer) between the two variables $(\mathrm{OR}>1)$, while others showed decreasing risk of prostate cancer with high vegetable consumption $(\mathrm{OR}<1)$.Thus the pooled odds ratio $(0.94)$ implies a reduced risk of prostate cancer with high intake of vegetable. However, from the result the pvalue for the overall effect $(Z)$ is significant if $p<0.05$ and from the analysis above, the p-value is 0.20 thus it is not statistically significant but there is a decreased risk of prostate cancer with high intake of vegetables which favours the experimental/study group.

In figure 2 the number of participants who consumed fruits was compared between case and control groups and the case had higher consumption of 1819 to 1810 of control. The result indicated that the Cochran's Q represented by Chi-square (10.05), p-value $(0.04)$ and $\mathrm{P}$ Index $(60 \%)$ is significant for heterogeneity. This means that it can be assume that the studies taken as a group gave a summary estimate which varies from the individual study effect estimate. Therefore, this implies that there is variation between studies which is significant and not due to only sampling or random error. Since all the studies show a significant heterogeneity, it will not be appropriate to use the above fixed effect model for the meta-analysis. The pooled odds ratio under the fixed effect model is 1.04 at $95 \%$ confidence interval $(0.95-1.15)$. The $\mathrm{p}$ value of the overall effect $(\mathrm{Z})$ from the result is 0.39 , which indicates that it is not statistically significant. The odds ratio of the individual studies had 3 studies compared to 2 which fell above 1.0 and a range of 0.60 to 1.13. This implies that these studies show more positive relationship (that is high intake of fruits increases the risk of getting prostate cancer) between the two variables $(\mathrm{OR}>1)$ than a negative one. The forest plot shows a clear and significant disparity in the weight distribution of the individual studies and the pooled odds ratio (1.04) greater than 1 as earlier mentioned above favours the control for this analysis.

Another analysis was done based on the presence of heterogeneity and a random effect model was used to analysis the comparison, between high fruits and prostate cancer risk with the result shown in figure 3. The result in figure 3 indicates that the Cochran's Q (10.05), P-value (0.04) and $P$ Index (60\%) are also significant for heterogeneity. It can equally be seen that because a variation does exist, the between study variance $\mathrm{Tau}^{2}$ or $\left(\mathrm{i}^{2}\right)$ is indicated as 0.02 in this analysis. The same Mantel-Haenszel method was used in both analyses, since this study has quantified the effect size estimate or measure in odds ratio. The resulting pooled odds ratio using the random effect model was 0.98 at $95 \%$ confidence interval $(0.82$ 1.17).while the $\mathrm{p}$-value for the overall effect $(\mathrm{Z})$ is 0.80 , which shows no statistical significant and a negative 
relationship or association between high fruits and risk of prostate cancer which favours the experimental/study group. The forest plot is quite different from the previous one described by using a fixed effect model. It clearly shows a reduced disparity in the weight distribution of the individual studies and the pooled odds ratio (0.98) of less than 1 .

Figure 4 shows a Cochran's Q, p-value and $\mathrm{I}^{2}$ index of $4.87,0.30$ and $18 \%$ respectively which are not significant for heterogeneity among all the studies. Therefore a fixed effect model will be appropriate for combining their odds ratio to obtain a pooled odds ratio. The pooled odds ratio is 1.04 with a $95 \%$ confidence interval of (0.95-1.15) which indicates a positive relationship or an increased risk of prostate cancer with low intake of vegetables $(\mathrm{OR}>1)$. The $\mathrm{p}$-value for the overall effect is 0.40 , which is not statistically significant and this analysis is seen to favour the control. The weight distribution on the forest plot shows high disparity and the pooled odds ratio is greater than 1 .

Similarly, figure 5 indicate that the Cochran's Q (11.3 1),p-value (0.02) and the $P$ index $(65 \%)$ which is significant for heterogeneity among the studies and thus it will be appropriate to use random effect model to obtain the pooled odds ratio. The pooled odds ratio using the Mantel-haenszel is 0.94 with $95 \%$ confidence interval of (0.85-1.04). The p-value is 0.23 , which indicates no statistical significant of the overall effect $(\mathrm{Z})$ and negative association of low fruits with risk of prostate cancer $(\mathrm{OR}<1)$. But using the random effect model for the same data (figure 6), the Cochran's Q, Pvalue and $\mathrm{I}^{2}$ Index still remains the same and indicating heterogeneity. The pooled odds ratio is 1.02 with $95 \%$ confidence interval of (0.84-1.23). The p-value is 0.85 showing no statistical significant for the overall effect (Z) and an increased risk of prostate cancer with low fruits intake which favours the control is obtained as shown in figure 6 .

Table-1: Number of people who were exposed to high vegetable consumption and risk of prostate cancer

\begin{tabular}{|c|c|c|c|c|c|c|c|}
\hline \multirow[t]{3}{*}{$\mathbf{S} / \mathbf{N}$} & \multirow[t]{3}{*}{ Author } & \multirow[t]{3}{*}{ Year } & \multirow[t]{3}{*}{ Location } & \multicolumn{2}{|c|}{ Study group } & \multicolumn{2}{|c|}{ Control group } \\
\hline & & & & Case $(\mathrm{pc}+)$ & High veg & Control (pc-) & High \\
\hline & & & & & & & veg \\
\hline 1 & Villeneuve $e t$ al. & 1999 & Canada & 1623 & 692 & 1623 & 706 \\
\hline 2 & Jain et al. & 1999 & Canada & 617 & 296 & 636 & 318 \\
\hline 3 & Cohen et al. & 2000 & USA & 628 & 277 & 602 & 268 \\
\hline 4 & Sonoda et al. & 2004 & Japan & 140 & 71 & 140 & 70 \\
\hline \multirow[t]{2}{*}{5} & Deneo-pellegrini et al. & 1999 & Uruguay & 175 & 75 & 233 & 126 \\
\hline & \multicolumn{3}{|l|}{ TOTAL } & 3183 & 1411 & 3234 & 1488 \\
\hline
\end{tabular}

Table-2: Number of people who were exposed to high fruits consumption and risk of prostate cancer

\begin{tabular}{|c|c|c|c|c|c|c|c|}
\hline \multirow[t]{2}{*}{$\mathbf{S} / \mathbf{N}$} & \multirow[t]{2}{*}{ Author } & \multirow[t]{2}{*}{ Year } & \multirow[t]{2}{*}{ Location } & \multicolumn{2}{|c|}{ Study group } & \multicolumn{2}{|c|}{ Control group } \\
\hline & & & & Case $(p c+)$ & $\begin{array}{l}\text { High } \\
\text { fruits }\end{array}$ & Control (pc-) & $\begin{array}{l}\text { High } \\
\text { Fruits }\end{array}$ \\
\hline 1 & Villeneuve et al. & 1999 & Canada & 1623 & 1014 & 1623 & 967 \\
\hline 2 & Jain et al. & 1999 & Canada & 617 & 326 & 636 & 318 \\
\hline 3 & Cohen et al. & 2000 & USA & 628 & 341 & 602 & 326 \\
\hline 4 & Sonoda et al. & 2004 & Japan & 140 & 63 & 140 & 70 \\
\hline 5 & Deneo- pellegrini et al. & 1999 & Uruguay & 175 & 75 & 233 & 129 \\
\hline & TOTAL & & & 3183 & 1819 & 3234 & 1810 \\
\hline
\end{tabular}

Table-3: Number of people who were exposed to low vegetable consumption and risk of prostate cancer

\begin{tabular}{|l|l|l|l|l|l|l|l|}
\hline S/N & Author & Year & Location & \multicolumn{2}{|l|}{ Study group } & \multicolumn{2}{l|}{ Control group } \\
\cline { 5 - 9 } & & & & Case $(\mathrm{pc}+)$ & Low veg & Control (PC-) & Low veg \\
\hline 1 & Villeneuve et al. & 1999 & Canada & 1623 & 908 & 1623 & 911 \\
\hline 2 & Jain et al. & 1999 & Canada & 617 & 321 & 636 & 318 \\
\hline 3 & Cohen et al. & 2000 & USA & 628 & 351 & 602 & 334 \\
\hline 4 & Sonoda et al. & 2004 & japan & 140 & 69 & 140 & 70 \\
\hline 5 & Deneo-pellegrini et al. & 1999 & Uruguay & 175 & 100 & 233 & 107 \\
\hline & & & & & & & \\
\hline & TOTAL & & $\mathbf{3 1 8 3}$ & $\mathbf{1 7 4 9}$ & $\mathbf{3 2 3 4}$ & $\mathbf{1 7 4 0}$ \\
\hline
\end{tabular}


Table-4: Number of people who were exposed to low fruits and risk of prostate cancer

\begin{tabular}{|c|c|c|c|c|c|c|c|c|}
\hline & Author & Year & Location & \multicolumn{2}{|c|}{ Study group } & \multicolumn{3}{|c|}{ Control group } \\
\hline & & & & Case & Low & \multicolumn{2}{|c|}{ Control } & Low \\
\hline & & & & $(p c+)$ & fruits & \multicolumn{2}{|c|}{ (pc-) } & fruits \\
\hline & Villeneuve et al. & 1999 & Canada & 1623 & 589 & \multicolumn{2}{|l|}{1623} & 650 \\
\hline 2 & Jain et al. & 1999 & Canada & 617 & 291 & 636 & \multicolumn{2}{|c|}{318} \\
\hline 3 & Cohen et al. & 2000 & USA & 628 & 287 & 602 & \multicolumn{2}{|c|}{276} \\
\hline 4 & Sonoda et al. & 2004 & Japan & 140 & 77 & 140 & \multicolumn{2}{|c|}{70} \\
\hline 5 & Deneo-pellegrini et al. & 1999 & Uruguay & 175 & 100 & 233 & \multicolumn{2}{|c|}{104} \\
\hline & \multicolumn{3}{|l|}{ TOTAL } & 3183 & 1344 & 3234 & \multicolumn{2}{|c|}{1418} \\
\hline
\end{tabular}

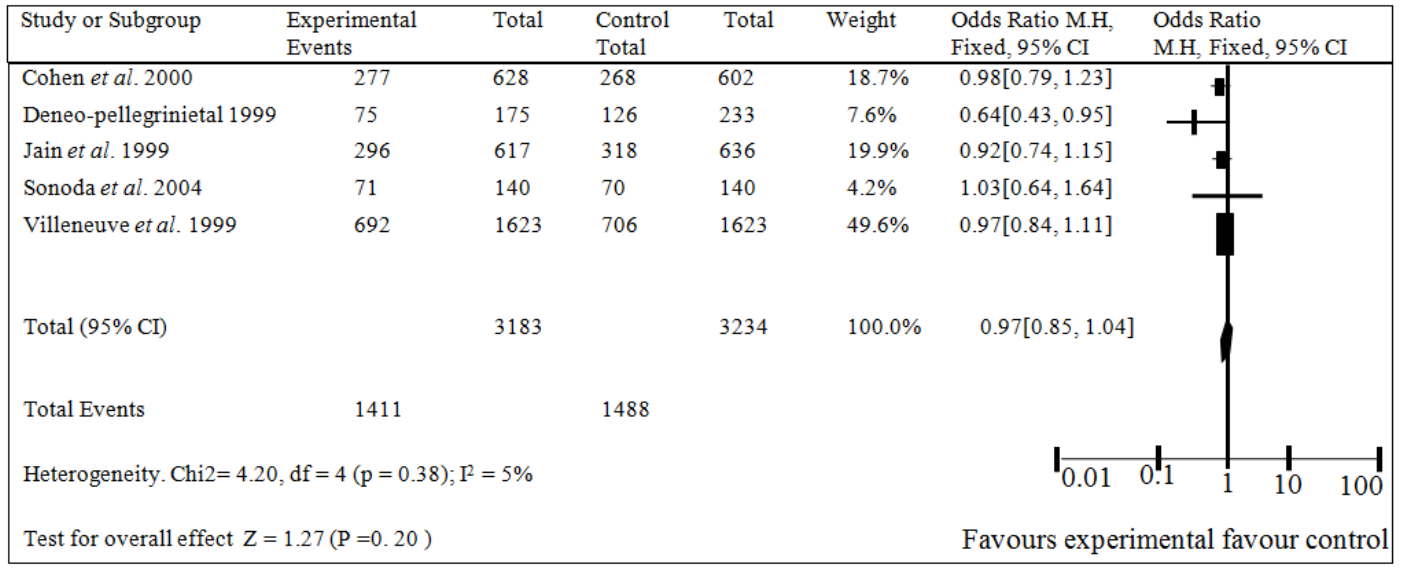

Fig-1: Comparison of High Intake of Fruits and Risk of Prostate Cancer SHOWING polled odds ratio (ORp), with a 95\% confidence interval and $\mathrm{Z}$ value

\begin{tabular}{|c|c|c|c|c|c|c|}
\hline Cohen et al. 2000 & 341 & 628 & 326 & 602 & $19.9 \%$ & $1.01[0.80,1.26]$ \\
\hline Study or Subgroup & $\begin{array}{l}\text { Experimental } \\
\text { Events }\end{array}$ & Total & $\begin{array}{l}\text { Control } \\
\text { Total }\end{array}$ & Total & Weight & $\begin{array}{l}\text { Odds Ratio } \\
\text { M.H, Fixed, } 95 \% \text { CI }\end{array}$ \\
\hline Deneo-pellegrinietal 1999 & 75 & 175 & 129 & 233 & $8.3 \%$ & $0.60[0.41,0.90]$ \\
\hline Jain et al. 1999 & 326 & 617 & 318 & 636 & $19.3 \%$ & $1.12[0.90,1.40]$ \\
\hline Sonoda et al. 2004 & 63 & 140 & 70 & 140 & $5.0 \%$ & $0.82[0.51,1.31]$ \\
\hline Villeneuve et al. 1999 & 1014 & 1623 & 967 & 1623 & $47.5 \%$ & $1.13[0.98,1.30]$ \\
\hline Total $(95 \% \mathrm{CI})$ & & 3183 & & 3234 & $100.0 \%$ & $1.04[0.95,1.15]$ \\
\hline Total Events & 1819 & & 1810 & & & \\
\hline \multicolumn{3}{|c|}{ Heterogeneity. $\mathrm{Ch}^{2}=10.05 \mathrm{df}=4(\mathrm{p}=0.04) ; 1^{2}=60 \%$} & & & & $\mathbf{I}_{0.01} \quad 0.1$ \\
\hline Test for overall effect $Z=$ & $=0.39)$ & & & & \multicolumn{2}{|r|}{ Favours experimental Favour control } \\
\hline
\end{tabular}

Fig-2: Comparison of High Intake of Fruits and Risk of Prostate Cancer Showing polled odds ratio (ORp), with a 95\% confidence interval and $Z$ value

\begin{tabular}{|c|c|c|c|c|c|c|c|}
\hline Study or Subgroup & $\begin{array}{l}\text { Experimental } \\
\text { Events }\end{array}$ & Total & $\begin{array}{l}\text { Control } \\
\text { Total }\end{array}$ & Total & Weight & $\begin{array}{l}\text { Odds Ratio M.H, } \\
\text { Fixed, } 95 \% \text { CI }\end{array}$ & $\begin{array}{l}\text { Odds Ratio } \\
\text { M.H, Fixed, } 95 \% \text { CI }\end{array}$ \\
\hline Cohen et al. 2000 & 341 & 628 & 326 & 602 & $23.2 \%$ & $1.01[0.80,1.26]$ & \\
\hline Deneo-pellegrinietal 1999 & 75 & 175 & 129 & 233 & $13.2 \%$ & $0.60[0.41,0.90]$ & \\
\hline Jain et al. 1999 & 326 & 617 & 318 & 636 & $23.4 \%$ & $1.12[0.90,1.40]$ & \\
\hline Sonoda et al. 2004 & 63 & 140 & 70 & 140 & $10.5 \%$ & $0.82[0.51,1.31]$ & \\
\hline Villeneuve et al. 1999 & 1014 & 1623 & 967 & 1623 & $29.7 \%$ & $1.13[0.98,1.30]$ & \\
\hline Total $(95 \% \mathrm{CI})$ & & 3183 & & 3234 & $100.0 \%$ & $0.97[0.82,1.17]$ & \\
\hline Total Events & 1411 & & 1488 & & & & \\
\hline \multicolumn{6}{|c|}{ Heterogeneity. $\mathrm{Tau}^{2}=0.02, \mathrm{Chi}^{2}=10.05(\mathrm{p}=0.04) ; \mathrm{I}^{2}=60 \%$} & 0 & 10100 \\
\hline \multicolumn{6}{|c|}{ Test for overall effect $Z=0.25(P=0.80)$} & favours experim & nental favour cont \\
\hline
\end{tabular}

Fig-3: Comparison of High Intake of Fruits and Risk of Prostate Cancer SHOWING polled odds ratio (ORp), with a 95\% confidence interval and $\mathrm{Z}$ value using the random effect model. 


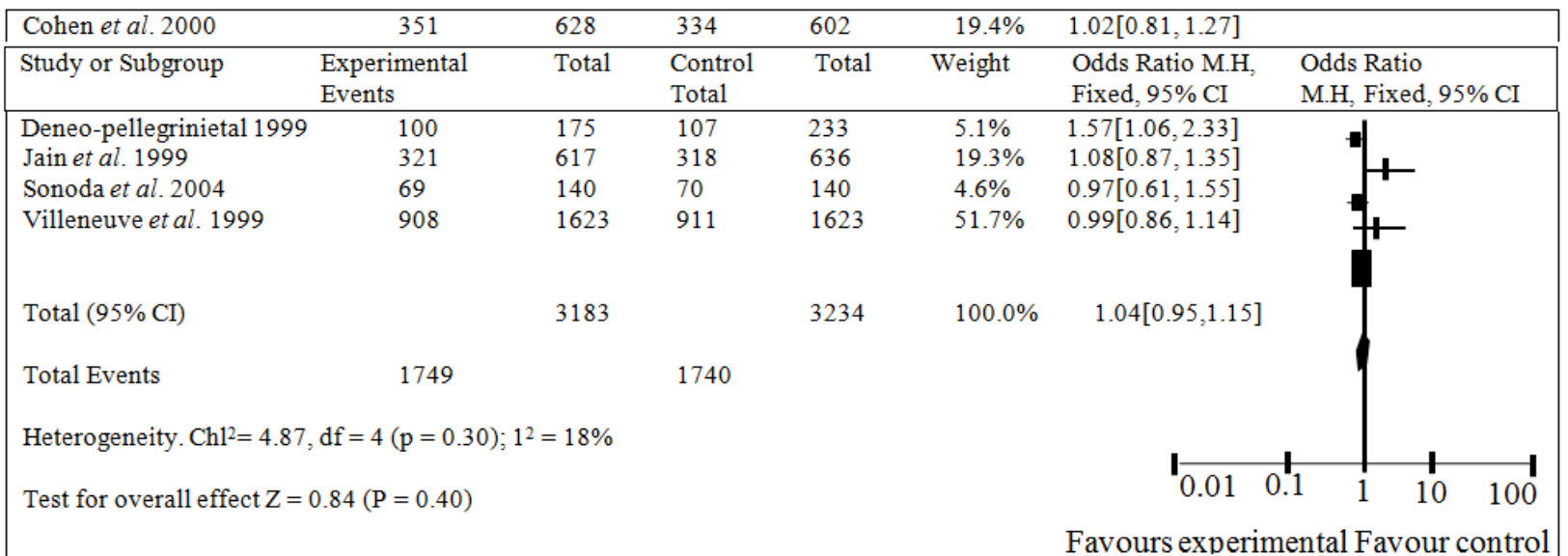

Fig-4: Comparison of High Intake of Fruits and Risk of Prostate Cancer SHOWING polled odds ratio (ORp), with a $95 \%$ confidence interval and $Z$ value using the random effect model

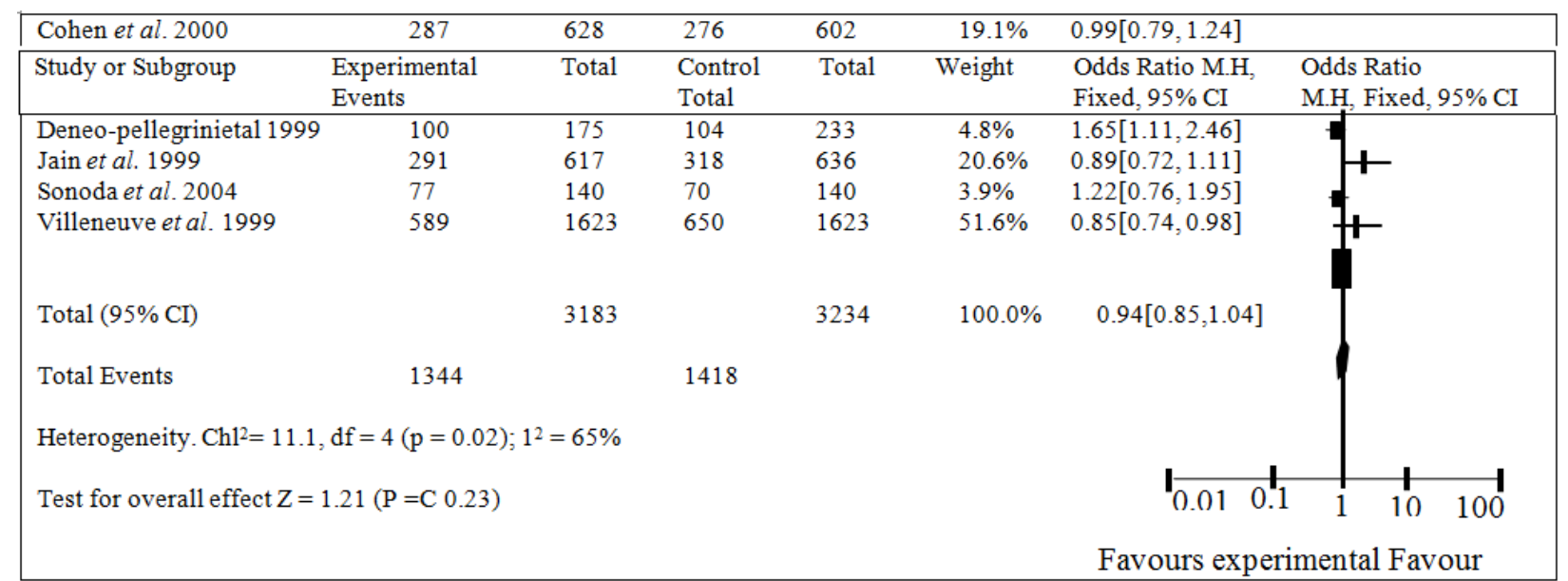

Fig-5: Comparison of High Intake of Fruits and Risk of Prostate Cancer showing polled odds ratio(ORp), with a 95\% confidence interval and $Z$ value using the random effect model

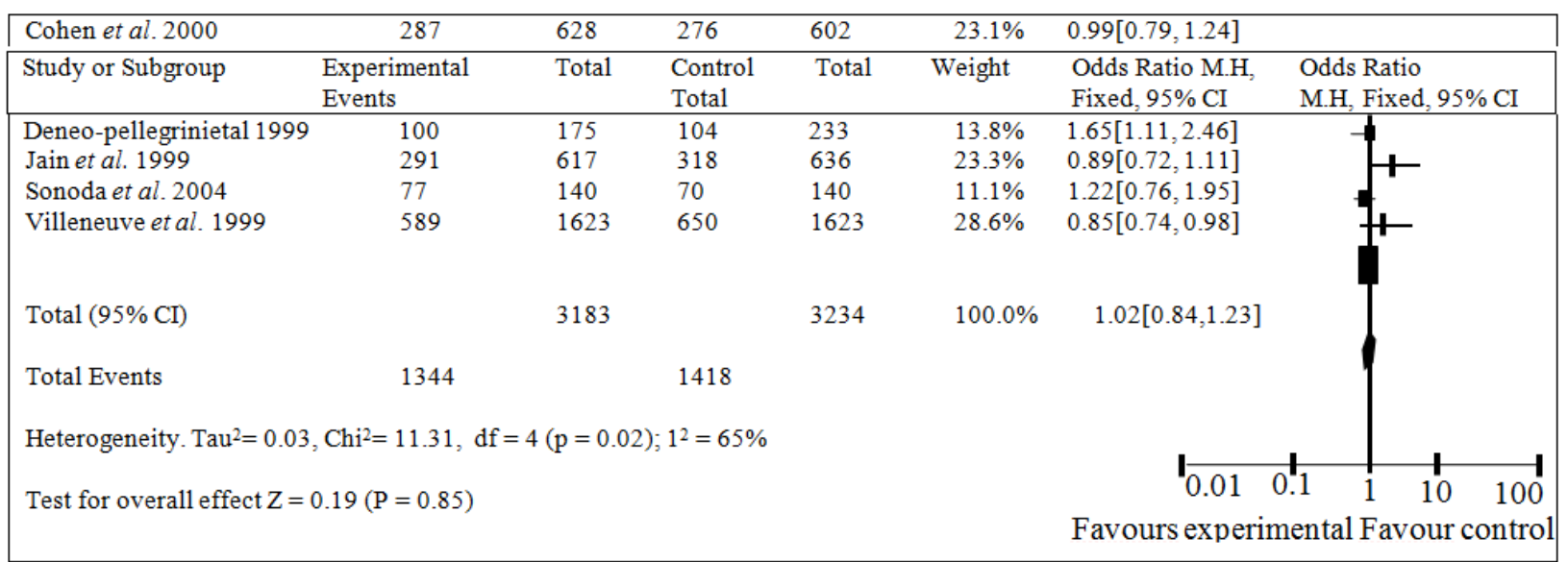

Fig-6: Comparison of High Intake of Fruits and Risk of Prostate Cancer showing polled odds ratio (ORp), with a $95 \%$ confidence interval and $Z$ value using the random effect model

\section{Discussion}

This research examined and analysed the existing research findings on the association between high intake of fruits and vegetables and the risk of developing prostate cancer in men using meta-analysis.
The findings of 5 articles were summarised by combining their individual odds estimates to give an overall estimate of the effect size [38].while 2 of the studies were conducted in Canada, one each was carried out in America, Japan and Uruguay. The result of this 
meta-analysis of high intake of vegetables gave a pooled odds ratio of 0.94 by Mantel-Haenszel method in the absence of heterogeneity was compared to the pooled odds ratio for low intake of vegetables of 1.04 with risk of prostate cancer. This result implies that there is a reduced risk of developing prostate cancer in men who consumed high quantity of vegetables than men who consume low quantity or none. The result of this meta-analysis is consistent with the general body of research showing a strong association between high intakes of vegetables with risk of prostate cancer. This finding of a protective effect agrees with the findings of other researchers who observed that increasing the quantity of vegetables consumed above the recommended daily $200 \mathrm{~g}$ reduces the risk of developing prostate cancer in men $[9,15,43,49]$. In the other analysis done for both high and low intake of fruits and prostate cancer risk, the pooled odds ratio using the Mantel-Haenszel method under random effect model owing to the presence of heterogeneity in both analyses is 0.98 and 1.02 respectively. This result implies that men who consume high fruits were less at risk of developing prostate cancer than those who took less fruits or none. This finding of a protective association agrees also with some findings of other researchers who have conducted studies on both variables [50-52].

The result of this meta-analysis agrees with the result of the odds ratio of the included study carried out by Deneo-pellegrini et al. [51]. This case-control study by Deneo-pellegrini et al. [51] observed a reduced risk for prostate cancer with consumption of vegetables as a result of the presence of lutein, a carotenoid and vitamins $\mathrm{C}$ and $\mathrm{E}$ in vegetables which gave a protective effect through their combined antioxidant action. Similarly, the result of this meta-analysis was also found to be consistent with the result of the odds ratio for the case-control study conducted by Jain et al [53], who observed a reduced risk for prostate cancer with consumption of green leafy and cruciferous vegetables as a result of lutein that is present in vegetables which acted through antioxidant effect on prostatic cells.

The study finding of Cohen et al. [9] which was one of the case-control studies used in these metaanalyses also agrees with the result of reduced risk of prostate cancer with vegetables consumption. In their study, Cohen et al. [9] and his colleagues observed that the reduced risk noted was attributed to the combined effect of Lutein, Zeaxanthin both carotenoids found in green leafy and dark green vegetables and isothiocyanate found only in cruciferous vegetables. But, according to the body of literature, the evidence for a protective effect of vegetables against prostate cancer based on case-control studies is inconsistent. However, the findings of these case-control studies included in this meta-analysis is consistent with other past and recent research findings. For example, the findings of this meta-analyses is consistent with the findings of an earlier study done in Japan by Ohno et al. [54] who observed an inverse association with green vegetables and risk of prostate cancer due to the effect of betacarotene and vitamin A. Another study conducted in South Africa by Walker et al. [55] who observed an inverse association with carrots, spinach and cabbage and risk of prostate cancer in patients in Soweto was as a result of the beta-carotene and isothiocyanate present in them. Furthermore in a recent study by Kolonel et al. [43] he equally observed an inverse association for vegetables overall which he attributed to the protective effect caused by the presence of beta-carotene,alphacarotene and isothiocyanate in cruciferous vegetables. Although,the results of these above studies have clearly shown a strong inverse association between high consumption of vegetables and especially for cruciferous vegetables with risk of prostate cancer, none of them is a prospective or cohort study. In 1997, the world cancer research fund in conjunction with the American institute for cancer research, reported that the result findings been generated by case-control studies were equivocal as a result of emanating contrary view from prospective studies that vegetables were not associated with risk of developing prostate cancer.

One of the argument was presented by Shibata et al [56] with the findings of a study of 1335 prostate cancer cases whom were diagnosed after 8 years follow-up with a baseline consumption of vegetables, fruits, beta-carotene and vitamin $\mathrm{C}$ that resulted in no evidence of a protective effect after adjusting for confounders. Other research findings by Takachi et al. [5], Hsing et al. [16], Stram et al. [37] and Giovannucci et al. [52], also found no association between vegetables and risk of prostate cancer. However the result of this meta-analysis can be seen to agree with documented prospective studies that observed an inverse association for vegetables with risk of prostate cancer. Giovannucci et al. [18] observed a non-statistically significant inverse association for cruciferous vegetables intake and risk of early prostate cancer which he attributed to the protective effect of isothiocyanate presence in them. A recent prospective study by Kirsh et al [10] observed a strong statistically significant inverse association for cruciferous vegetables intake and risk of late or advanced prostate cancer which was due to the protective effect of both isothiocyanate and flavonoid.

Thus, it can be convincingly said that all the study findings that were consistent with the findings of this meta-analysis that produced an inverse association was attributed to the presence of these nutrients or constituents found in vegetables; lutein, Zeaxanthin, isothiocyanate, flavonoid, beta-carotene, alphacarotene, vitamin $\mathrm{C}$ and $\mathrm{E}$. These studies strongly support the hypothesis that high intake of vegetables reduces the risk of prostate cancer in men. Therefore it can be concluded that the inverse association or reduced risk of prostate cancer with high intake of vegetables observed by this meta-analysis is as a result of the 
activities of these constituents (lutein, Zeaxanthin, isocyanate, flavonoid, beta-carotene, alpha-carotene, vitamins $\mathrm{C}$ and $\mathrm{E})$.

In the second analysis, involving the association of high intake of fruits and risk of prostate cancer, the result of this meta-analysis observed that there was reduced risk for prostate cancer with high consumption of fruits and this finding agrees with two of the included studies used [24, 51]. Deneo-pellegrini et al. [51] observed a reduced risk for prostate cancer with consumption of fruits in his study findings as a result of vitamin $\mathrm{C}$ that is present in fruits. However, this result of reduced risk or inverse association between fruits intake and prostate cancer incidence has been inconsistent and very controversial in reports and reviews been carried out and documented in the body of literature, where most studies be it a case-control or cohort study has held contrary views to the findings of this meta-analysis. Some research findings have shown increased risk or association between high intake of fruits and prostate cancer $[17,44,53]$, while others have shown no association [24 and 37]. On the other hand, the result of this meta-analysis agrees with the findings of a study conducted by Giovannucci et al. [52] who observed a reduced risk for prostate cancer with high consumption of fruits as a result of high level of fructose that induces active vitamin $\mathrm{D}$ which acts on the prostatic cells. This finding agrees with an earlier study conducted by Mill et al. [57] that indicated an inverse association for prostate cancer with high intake of dried fruits like raisin which apparently is compose of high fractose, thus giving credence to this present metaanalysis that has shown an inverse or protective association for fruits. Similarly the study conducted by Sonoda et al. [24] agreed with the result findings of this meta-analysis by observing a reduced risk for prostate cancer but with soyabean and soya-products not for fruits. He attributed the reduced risk of prostate cancer as a result of the presence of isoflavone, which is a phytoestrogen commonly found in legumes. Although, the focus of this hypothesis is not on legumes but this finding of this meta-analysis has revealed that legumes undoubtedly have potential protective effect with prostate cancer incidence. This result is consistent with several studies conducted in Asian population where legumes is eaten as their stable diet and has been hypothesized to be the contributory factor for their low incidence rate of prostate cancer [43].

Based on the above discussion, it can be said that the study findings of these two studies that were consistent with the findings of this meta-analysis was attributed to by the presence of these nutrients found in fruits and legumes; vitamin $\mathrm{C}$, fructose and Isoflavone. Thus this study supports the hypothesis that high intake of fruits reduces the risk of developing prostate cancer in men. Therefore, it can be concluded that the inverse association of prostate cancer with high intake of fruits observed by this meta-analysis is as a result of the activities of these constituents (vitamin $\mathrm{C}$, fructose and Isoflavone).

In summary, in this pooled analysis of 5 casecontrol studies, the index study found that inverse association between high vegetables and fruits intake and prostate cancer risk where due to the individual constituents (lutein, Zeaxanthin, isothiocyanate, fructose, isoflavone, flavonoid, beta-carotene, alphacarotene and vitamins $\mathrm{C}$ and $\mathrm{E}$ ) and their interaction with each other to produce a protective effect against prostate cancer cells. In addition, the cruciferous vegetables were observed to be associated with more of this reduced risk in vegetables as a group and more so with early stage prostate cancer. Thus if this association is found to be casual, a possible means of reducing this cancer can be achieve by instituting an appropriate early dietary pattern of cruciferous vegetables in early adulthood as a form of primary prevention would go a long way to stem the rising tide of this disease worldwide.

\section{CONCLUSION}

This quantitative meta-analysis tested the hypothesis that high consumption of fruits and vegetables reduces the risk of prostate cancer in men by aggregating and analysing the data obtained from primary studies. A systematic literature search for relevant studies was carried out from the multiple databases retrieving 5 inclusion studies. The technique of meta-analysis was then applied to aggregate the individual findings of these 5 studies to obtain a summary estimate which found that only men with high or total intake of vegetables and fruits had a reduced risk or an inverse association of developing prostate cancer than men that did not. This meta-analysis found a weak non-statistically significant inverse association between high intakes of vegetables especially cruciferous vegetables and fruits and risk of prostate cancer. This meta-analysis indicated that this observed reduce risk with high or total intake of vegetables is possibly due to the presence of cruciferous vegetables, while the observed reduce risk with high fruits is possibly due to the presence of fruits high in fructose like apple, pears, grapes, watermelon, raisins, etc. Thus, men who are on diet which contains cruciferous vegetables and fruits would have decrease incidence rate of prostate cancer.

\section{RECOMMENDATIONS}

This meta-analysis considered vegetables and fruits in general and their effect on prostate cancer incidence and observed that cruciferous vegetables and fruits rich in fructose like apple, grapes, raisins, watermelon were implicated to have more protective effect than others. Thus, it is recommended that a study be done on specific vegetables or fruit to further evaluate their effect on prostate cancer in the future. 


\section{REFERENCES}

1. Kumar, P., \& Clark, M. (2005). Clinical medicine. $6^{\text {th }}$ ed. Elsevier Sundsers.

2. Nomura, A. M., \& Kolonel, L. N. (1991). Prostate cancer: a current perspective. Epidemiologic reviews, 13(1), 200-227.

3. Greenwald, P., Clifford, C.K., \& Milner, J.A. (2001) Diet and Cancer prevention. European Journal of Cancer [online] 37 pp948-965 [Accessed 17 December 2011]. Available at<http://www.ejconline.com $>$.

4. Globocan International Agency for Research on Cancer. (2008). Ca«cer Facts and Figures sheet, \{online\}, Accessed 7, July, 2011, available at :http://globocan.iarc.fr/factsheets/cancers/prostate.a sp

5. Takachi, R., Inoue, M., Sawada, N., Iwasaki, M., Sasazuki, S., Ishihara, J., ... \& Japan Public Health Center-Based Prospective Study Group. (2009). Fruits and vegetables in relation to prostate cancer in Japanese men: the Japan Public Health CenterBased Prospective Study. Nutrition and cancer, 62(1), 30-39.

6. American Cancer Society.(2003).Cancer Facts and Figures. Atlanta, GA.

7. Clinton, S.K., \& Giovannucci, E. (1998). Diet, Nutrition and Prostate cancer .(online).(accessed 12 June 2011).Available at:http://ebscohost.com.

8. Villeneuve, P.J., Johnson, K. C., Kreiger, N., \& Mao, Y. (1999). Risk factors for prostate cancer: results from the Canadian national enhanced cancer surveillance systematic cancer causes and control. (online). 10pp5 (accessed 13 february 2012) available at:http://ebscohost.com

9. Cohen, J.H., Kristal, A.R., \& Stanford, J.L. (2000).Fruits and Vegetables intake and Prostate cancer risk. Journal of the national cancer institute.(online) 92(1)(accessed 28 August 2011).Available at:http://ebscohost.com.

10. Kirsh, V. A., Peters, U., Mayne, S. T., Subar, A. F., Chatterjee, N., Johnson, C. C., \& Hayes, R. B. (2007). Prospective study of fruit and vegetable intake and risk of prostate cancer. Journal of the National Cancer Institute, 99(15), 1200-1209.

11. American National Cancer Institute. (2012). The prostate cancer outcome study:fact sheet, (online).(accessed 10 June,2012). Available at: http:// www.cancer.gov/.

12. Steinmetz, K.A., \& Potter, J.D. (1996).Vegetables, fruits and cancer prevention: a review. Journal of the American dietetic association (online)vol 96.no 10.(accessed2, march2012).Availableat: <http:// ebscohost.com>

13. Armstrong, B., \& Doll, R.(1975).Environmental factors and cancer incidence and mortality in different countries with special references to dietary practices. International journal cancer 15, pp 617-631.

14. Warmkessel, J.H. (2006). Comptemporary issues prostate cancer: a nursing perspective.
15. Jansen, M. C., Bueno-de-Mesquita, H. B., Feskens, E. J., Streppel, M. T., Kok, F. J., \& Kromhout, D. (2004). Quantity and variety of fruit and vegetable consumption and cancer risk. Nutrition and cancer, 48(2), 142-148.

16. Hsing, A. W., McLaughlin, J. K., Schuman, L. M., Bjelke, E., Gridley, G., Wacholder, S., ... \& Blot, W. J. (1990). Diet, tobacco use, and fatal prostate cancer: results from the Lutheran Brotherhood Cohort Study. Cancer research,50(21), 68366840.

17. Schuurman, A. G., Goldbohm, R. A., Dorant, E., \& van den Brandt, P. A. (1998). Vegetable and fruit consumption and prostate cancer risk: a cohort study in The Netherlands. Cancer Epidemiology and Prevention Biomarkers, 7(8), 673-680.

18. Giovannucci, E., Rimm, E. B., Liu, Y., Stampfer, M. J., \& Willett, W. C. (2003). A prospective study of cruciferous vegetables and prostate cancer. Cancer Epidemiology and Prevention Biomarkers, 12(12), 1403-1409.

19. American Institute of cancer research. (1997). Prostate in food nutrition and the prevention of cancer: A global perspective Washington, DC; Amercian institute cancer research ,8pp 310-323.

20. Vainio, H., \& Weiderpass, E. (2006). Fruit and vegetables in cancer prevention. Nutrition and cancer, 54(1), 111-142.

21. Schaid, D.J. (2004). The complex epidemiology of prostate cancer. Humor molecular genetic.13 spec nol;r!03-121.

22. Herr, I., \& Büchler, M. W. (2010). Dietary constituents of broccoli and other cruciferous vegetables: implications for prevention and therapy of cancer. Cancer treatment reviews, 36(5), 377383.

23. WHO. (2004). Global burden of diseases, (online), (accessed 10 June,2012). Available at: http:// www.who.int/healthinfo/global_burden_disease/G BD

24. Sonoda, T., Nagata, Y., Mori, M., Miyanaga, N., Takashima, N., Okumura, K., ... \& Takahashi, A. (2004). A case-control study of diet and prostate cancer in Japan: possible protective effect of traditional Japanese diet. Cancer science, 95(3), 238-242.

25. Eduardo, I.C., Shahrokh, F.S., \& Kevin, M.S. (2004). Molecular diagnosis of prostate cancer. Current Prostate Reports,4ppll-7.

26. Doddamam, C.D., \& Kayastha, B.A. (2008). prostate cancer- What is new? Journal national cancer institute [online] 64(1) pp.52-56 [Accessed 15 December 2011]. Available at<http://www.sciencedirect.com>.

27. Partin, A.W., \& Carter, H.B. (2002). Diagnosis and staging of prostate cancer.In:Walsh.P, Ratik.A.P, Tarracott, V. Wein.AJ, editors. CampeH's Urology. ${ }^{\wedge}$ ed. Philadlphia:W.B Saunders; 8pp 3055-80

28. Guilloneau, B., Fettouh, H., Baumert, H., 
Cathelineau, X., \& Doublet, J. D. (2003). Laparoscopic radical Prostatectomy and the VIP technique: an interim analysis of results and technical points. Urology; $61 \mathrm{pp} 15-20$.

29. Sternberg, C.N.(2003). What's new in the treatment of advanced prostate cancer?. European journal cancer. 39, 136-46.

30. Susan, H. (2006). Importance of fruits and vegetables in cancer prevention. National perspective Journal of the council on nutrition of the American Chiropractic Association. 29(3) pp 37-46.

31. Ames B.N. (1998). Micronutrients prevent cancer and delay aging. toxicology letter, 102-103, 5-18.

32. Riboli, E., \& Norat, T.(2001). Cancer prevention and diet: opportunities in Europe. Public health nutrition, 4(2\415-411

33. Evans, P., \& Halliwell, B. (2001). Micronutrients:oxidant/antioxidant status. British journal of' Nutrition, 85, suppl.2.S67-S74.

34. Cooper, D. A., Eldridge, A. L., \& Peters, J. C. (1999). Dietary carotenoids and lung cancer: a review of recent research. Nutrition reviews, 57(5), 133-145.

35. Crawford, E.D. (2003). Epidemiology of prostate cancer. Urology (online) 62. (Accessed 23 January, 2012). Available at:http://sciencedirect.com.

36. Kristal. A., \& Lampe, J.W. (2002). Brassica vegetables and prostate cancer risk: a review of the epidemiological evidence. Nutrition and cancer journal. (Online).42(1).1-9(accessed 14 january,2012).Available at :http://sciencedirect. Com

37. Stram, O.D., Hankin, J.H., Wilkens, R.L., Park, S., Henderson, B.E., Nomura, A.M.Y., Pike, M.C., \& Kolonel, N.L. (2006). Prostrate Cancer incidence and the intake of fruits, vegetables and related micronutrients: the multi-ethnic cohort study. Cancer causes control [online] 17 pp. 1193-1207 [Accessed 25 February 2012]. Available athttp://www.sciencedirect.com>.

38. Sutton, A.J., Abrams, K.R., Jones, D.R., Sheldon,T.A., Song, F.(2000).Methodsfor Metaanalysis in Medical Research. West Sussex: Wiley.

39. Egger, M., Smith, G.D., \& Altman, D.G.(2001). Systematic Reviews in Health care:meta-analysis in context. $2^{\text {nd }}$ ed. London:BMJ books.

40. Leandro, G. (2005). Meta-analysis in Medical Research, Massachusetts: Blackwell Publishing Inc.

41. Riboli, E., \& Norat, T.(2001). Cancer prevention and diet: opportunities in Europe. Public health nutrition, 4(2\415-411

42. Ross, R. K., Shimizu, H., Paganini-Hill, A., Honda, G., \& Henderson, B. E. (1987). Case-control studies of prostate cancer in blacks and whites in southern California. Journal of the National Cancer Institute, 78(5), 869-874.

43. Kolonel, L. N., Hankin, J. H., Whittemore, A. S., Wu, A. H., Gallagher, R. P., Wilkens, L. R., ... \&
Paffenbarger, R. S. (2000). Vegetables, fruits, legumes and prostate cancer: a multiethnic casecontrol study. Cancer Epidemiology and Prevention Biomarkers, 9(8), 795-804.

44. Marchand, L. L., Hankin, J. H., Kolonel, L. N., \& Wilkens, L. R. (1991). Vegetable and fruit consumption in relation to prostate cancer risk in Hawaii: a reevaluation of the effect of dietary betacarotene. American journal of epidemiology, 133(3), 215-219.

45. Giovannucci, E., Ascherio, A., Rimm, E. B., Stampfer, M. J., Colditz, G. A., \& Willett, W. C. (1995). Intake of carotenoids and retino in relation to risk of prostate cancer. JNCI Journal of the National Cancer Institute, 87(23), 1767-1776.

46. Graham, S., Haughey, B., Marshall, J., Priore, R., Byers, T., Rzepka, T., Mettlin, C., \& Pontes, J,E. (1983). Diet in the epidemiology of cancinoma of the Prostrate. National Cancer Institute [online]70 pp.687-692 [Accessed 3 January 2012]. Avaialble at $<$ http//www.sciencedirect.com $>$.

47. Lipsey, M.W., \& Wilson, D.B. (2001). PracticalMeta-analysis. California: Sage Publication Inc.

48. Glasziou, P., Irwig, L., Bain, C., \& Colditz, G. (2001) Systematic Reviews in Health Care. Cambridge: Cambridge University Press.

49. Riboli, E. and Norat, T (2003) Epidemiology evidence of the protective effect of fruit and vegetables on cancer risk. American Journal of clinical nutrition[on\me] 78 pp.559-65 [Accessed 12 March 2012].Available at $<$ http://www.sciencedirect.com>.

50. Benetou, V., Orfanos, P., \& Lagiou, P. (2008). Vegetables and fruits in relation to cancer risk: Evidence from the Greek EPIC Cohort study. Cancer epidemiology biomarkers and prevention [online] 17(2) pp 387-392 [ Accessed 12 March 2012 ] Available at : < http:// epirev.oxfordj ournals.org>

51. Deneo-Pellegrini, H., De Stefani, E., Ronco, A., \& Mendilaharsu, M. (1999). Foods, nutrients and prostate cancer: a case-control study in Uruguay. British journal of cancer, 80(3), 591-597.

52. Giovannucci, E., Rimm, E. B., Wolk, A., Ascherio, A., Stampfer, M. J., Colditz, G. A., \& Willett, W. C. (1998). Calcium and fructose intake in relation to risk of prostate cancer. Cancer Research, 58(3), 442-447.

53. Jain, M. G., Hislop, G. T., Howe, G. R., \& Ghadirian, P. (1999). Plant foods, antioxidants, and prostate cancer risk: findings from case-control studies in Canada. Nutrition and cancer, 34(2), 173-184.

54. Ohno, Y., Yoshida, O., Oishi, K., Okada, K., Yamabe, H., \& Schroeder, F. H. (1988). Dietary $\beta$ carotene and cancer of the prostate: a case-control study in Kyoto, Japan. Cancer research, 48(5), 1331-1336.

55. Walker, A. R., Walker, B. F., Tsotetsi, N. G., 
Sebitso, C., Siwedi, D., \& Walker, A. J. (1992). Case-control study of prostate cancer in black patients in Soweto, South Africa. British journal of cancer, 65(3), 438-441.

56. Shibata, A., Paganini, H.A., Ross, R.K., \& Henderson, B.E. (1992). Intake of Vegetables, fruits, b-carotene, vitamin $\mathrm{C}$ and vitamin supplements and cancer incidence among the elderly; a prospective study. British Journal of cancer, 66 pp. 673-679 [Accessed 12 February 2012]. Available at $<$ http//www. sciencedirect. com>.

57. Mills, P. K., Beeson, W. L., Phillips, R. L., \& Fraser, G. E. (1989). Cohort study of diet, lifestyle, and prostate cancer in Adventist men. Cancer, 64(3), 598-604. 